\title{
Adherence to disease-specific drug treatment among patients with pulmonary arterial hypertension or chronic thromboembolic pulmonary hypertension
}

\author{
Barbro Kjellström (10 ${ }^{1,2}$, Anna Sandqvist ${ }^{3,4}$, Clara Hjalmarsson (10 5,6, \\ Magnus Nisell ${ }^{7}$, Per Näsman ${ }^{8}$ and Bodil Ivarsson (10 9
}

\begin{abstract}
Affiliations: 'Lund University, Dept of Clinical Sciences Lund, Clinical Physiology and Skåne University Hospital, Lund, Sweden. ${ }^{2}$ Cardiology Unit, Dept of Medicine, Karolinska Institutet, Stockholm, Sweden. ${ }^{3}$ Dept of Integrative Medical Biology, Umeå University, Umeå, Sweden. ${ }^{4}$ Janssen Cilag AB, Solna, Sweden. ${ }^{5}$ Dept of Molecular and Clinical Medicine, Sahlgrenska Academy, Gothenburg University, Gothenburg, Sweden. ${ }^{6}$ Dept of Cardiology, Sahlgrenska University Hospital, Gothenburg. Sweden. ${ }^{7}$ Lung Unit, Dept of Medicine, Karolinska Institute, and Karolinska University Hospital, Stockholm, Sweden. ${ }^{8}$ Center for Safety Research, KTH Royal Institute of Technology, Stockholm, Sweden. ${ }^{9}$ Dept of Clinical Sciences, Lund University Lund, Cardiothoracic Surgery, and Medicine Services University Trust, Region Skåne, Lund, Sweden.
\end{abstract}

Correspondence: Barbro Kjellström, Lund University, Dept of Clinical Sciences Lund, Clinical Physiology and Skåne University Hospital, Lund 221 00, Sweden. E-mail: barbro.kjellstromaki.se

\section{ABSTRACT}

Background: Pulmonary arterial hypertension (PAH) and chronic thromboembolic pulmonary hypertension $(\mathrm{CTEPH})$ require lifelong treatment. The aim of the present study was to investigate adherence to disease-specific treatment in patients with PAH or CTEPH.

Methods: The study comprised an adult population diagnosed with PAH $(n=384)$ or CTEPH $(n=187)$ alive in 2016-2017. The study utilised three registries: the Swedish PAH registry, the National Board of Health and Welfare, and Statistics Sweden. Withdrawals from pharmacies of disease-specific oral treatments were studied. Adherence was assessed as: 1) Number of days covered defined as the difference between the total number of daily dosages dispensed and the total number of days covered; and 2) Manual assessment by two persons that independently reviewed each patient's prescription fill history to detect anomalies or patterns of deteriorating or improving adherence over time.

Results: The mean age was $61 \pm 16$ years, $61 \%$ were female and mean time since diagnosis was 4.6 years. Adherence was $62 \%$ using the Number of days covered method and $66 \%$ by the Manual assessment method. Drug-specific adherence varied from $91 \%$ for riociguat to $60 \%$ for sildenafil. Good adherence was associated with shorter time since diagnosis in patients with PAH and with lower number of concomitant other chronic treatments in patients with CTEPH. Age, sex, socioeconomic status or number of pulmonary hypertension $(\mathrm{PH})$ treatments were not associated with adherence.

Conclusion: Adherence to oral disease-specific treatment was $60-66 \%$ and associated with time since diagnosis and number of concomitant chronic treatments. Sex, age or socioeconomic factors did not affect adherence.

@ERSpublications

Adherence to oral ERA and/or PDE-5i/SGC treatment is associated with time since diagnosis, while sex, gender, age and socioeconomic factors do not affect adherence in patients with PAH or CTEPH https://bit.ly/354NAOQ

Cite this article as: Kjellström B, Sandqvist A, Hjalmarsson C, et al. Adherence to disease-specific drug treatment among patients with pulmonary arterial hypertension or chronic thromboembolic pulmonary hypertension. ERJ Open Res 2020; 6: 00299-2020 [https://doi.org/10.1183/ 23120541.00299-2020]. 


\section{Introduction}

Pulmonary arterial hypertension (PAH) and chronic thromboembolic pulmonary hypertension (CTEPH) are serious, chronic diseases that require lifelong, disease-specific treatment [1]. The medical treatment is focused on improving symptoms, physical work ability, quality of life and survival. Over the last two decades, new drugs and optimised treatment strategies have increased survival and quality of life $[1,2]$. Pulmonary hypertension (PH)-targeted therapies include endothelin receptor antagonists (ERA), phosphodiesterase 5 inhibitors (PDE-5i) and soluble guanylate cyclase stimulators (SGCs), as well as prostacyclin analogues and a prostacyclin receptor agonist [1]. Current guidelines recommend monotherapy or upfront combination therapy, based on risk assessment $[1,3]$. Treatment side-effects can make it challenging to motivate patients to follow the prescribed treatment plan over time [4]. Medication adherence as low as 50\% has been reported among patients with PAH and CTEPH [5-8]. High age, the number of comorbidities and the integration of a specialist in pharmacology at the outpatient clinic have been shown to correlate with increased treatment adherence $[8,9]$. Treatment with monotherapy versus combination therapy, on the other side, is showing conflicting results $[8,10]$. In a recent Swedish survey, almost all patients with PAH or CTEPH said they understood why they took their drugs, but a third reported that they did not always take them according to the prescription [7]. Concerns about side-effects, reported by half of the study population, likely contributed to the low adherence. Further, a longer elapsed time since diagnosis and start of treatment related to lower self-reported treatment adherence [7].

The aim of the present study was to investigate, by utilising available national registries in Sweden, to what extent patients with PAH or CTEPH adhere to their disease-specific treatment. In addition, concomitant medical treatments and socioeconomic status were investigated.

\section{Methods}

The study included a retrospective population comprising patients registered in the Swedish PAH registry [11] with a diagnosis of PAH or CTEPH, aged $\geqslant 18$ years and alive January 2016 through December 2017. In Sweden, individual-level data for all residents can be linked across multiple national databases. This study was based on an interconnection between three available registries: Swedish Pulmonary Arterial Hypertension Register (SPAHR) [11], Socialstyrelsen (the National Board of Health and Welfare) [12] and Statistiska centralbyrån (Statistics Sweden) [13]. Socioeconomic factors including age, education, occupation, family situation and income during 2016 were used for the current analyses. The study complies with the Declaration of Helsinki and was approved by the Regional ethics committee in Lund, Sweden (LU 2016/766).

\section{SPAHR}

SPAHR was started in 2008 and constitutes an open continuous register of patients diagnosed with PAH or CTEPH according to the National Institute for Health and Care Excellence (NICE) classification [11]. All Swedish PAH/CTEPH expert centres participate and thus, SPAHR includes $>90 \%$ of all Swedish patients alive on January 1, 2000 and all subsequent newly diagnosed patients thereafter. SPAHR is approved by the National Board of Health and Welfare and by the Swedish Data Protection Authority. All patients were informed about their participation in SPAHR and had the right to decline.

\section{The National Board of Health and Welfare's pharmaceutical and population registries}

The National Board of Health and Welfare's pharmaceutical register covers all medicines that have been dispensed at pharmacies in Sweden. The registration takes place on an individual level. The National Board of Health and Welfare's population register contains information on socioeconomic factors that may affect the ability to pay for the treatment [12].

The Longitudinal Integration Database for Health Insurance and Labour Market Studies (LISA) LISA is part of Statistics Sweden and contains information on marital status, number of children, education level, socioeconomic index, vocational code, employment status, welfare benefits and income for all adult individuals in Sweden [13].

\section{Medical treatment and analyses of adherence}

Withdrawals of PH-specific treatments administered from pharmacies in 2016-2017 were studied. For each drug, adherence was assessed as follows.

1) "Number of days covered" [14]. This was defined as the difference between the total number of daily dosages dispensed from the pharmacy and the total number of days covered between the first to the last prescription fill. For good adherence, the difference between the dispensed daily dosages and the total number of days had to be one or less than one missed daily dosage per month. 
2) "Manual assessment" was performed by two persons that independently reviewed each patient's prescription fill history to detect anomalies or patterns such as deteriorating or improving adherence over time. When the assessments were not in agreement, the results were discussed and a consensus reached.

The studied PH-specific treatments included ERA, PDE-5i and SGCs. Adherence to prostacyclin analogues and the prostacyclin receptor agonist was not analysed due to the individualised dosages that are used for this group of drugs. Less than three concomitant prescription fills during the study period were excluded [14]. If a prescription was not filled for 180 days or more and the patient was on another PH-targeted treatment during that period that could explain why the prescription was not filled, the period was not considered non-adherence. Administration of $\mathrm{PH}$-specific treatments included: ambrisentan and macitentan once daily, bosentan and tadalafil twice daily, and sildenafil and riociguat three times a day.

Other concomitant medical treatments of interest were also studied and allocated as chronic treatment, e.g. treatment for chronic diseases with $\geqslant 3$ filled prescriptions in 1 year and as temporary treatment, e.g. treatment generally used for temporary diseases and with $\geqslant 1$ filled prescription in a year.

\section{Statistical methods and data management}

Descriptive statistics were used to characterise the data. Logistic regression analyses were performed, calculating odds ratios with 95\% confidence intervals. All analyses were carried out by use of SAS statistical software (SAS system for Windows 9.4; SAS Institute Inc., Cary, NC, USA).

\section{Results}

\section{Characteristics of the study population}

A total of 571 patients who were alive 2016-2017 were included in the analyses. Of those, 384 were diagnosed with PAH (idiopathic/hereditary (IPAH/HPAH) $n=201$, associated with connective tissue disease $n=86$, or congenital heart disease $n=66$, or other diseases $n=31$ ) and 187 with CTEPH. The mean age at time of diagnosis was $56 \pm 18$ years and at the time of the study $61 \pm 16$ years; the proportion of women was $61 \%$ (table 1 ). Mean time since diagnosis to study start was 4.6 years.

Half of the population had the highest degree of education as high school and the other half was equally divided between primary school and college/university degree. A majority of the study population was not working, and this was similar in men and women. Forty-five percent were married or had a registered partner and $22 \%$ of the households had children living at home, of which $12 \%$ were 18 years or older. The disposable household income was slightly below the average Swedish household income (table 1).

Of patients on monotherapy (38\%), 49\% were treated with PDE-5i or SGCs, and 37\% with ERA, while among patients on double therapy (37\%), 95\% were treated with ERA and PDE-5i or SGCs (table 2). Fifteen per cent did not have a registered prescription fill of a $\mathrm{PAH}$-specific drug, and a majority of those were patients with CTEPH. All patients with $\mathrm{CTEPH}$ and $66 \%$ of patients with $\mathrm{PAH}$ were prescribed anticoagulant treatment.

\section{Treatment adherence}

There were 443 patients that filled their prescriptions for ERA or PDE-5i, or a combination of ERA and PDE-5i, $\geqslant 3$ times during the study period and hence, could be included in the analyses of adherence (table 3). Adherence for the whole population was $62 \%$ using the Number of days covered method and in the subgroup analyses, $61 \%$ for PAH and $64 \%$ for CTEPH. Corresponding numbers for the Manual assessment method was $66 \%$ for all, 66\% for PAH and 67\% for CTEPH. Drug-specific adherence for the whole population varied from $91 \%$ that filled their prescriptions of riociguat to $60 \%$ that filled their prescriptions of sildenafil (table 3). Patients with combination treatment including prostacyclin therapy ( $\mathrm{n}=66$ ) had an adherence of 74 and $70 \%$ for the Number of days covered and Manual assessment methods, respectively (table 3). The Manual assessment detected more patients that missed two or less dosages per month than Number of days covered (figure 1).

Good adherence to oral PH-specific treatment, assessed by the Manual assessment method, was associated with shorter time since diagnosis in patients with $\mathrm{PAH}$ and to lower number of concomitant other chronic treatments in patients with CTEPH (table 4). Age, sex, socioeconomic status or number of PH treatments were not associated with adherence in either group (table 4). In addition, good adherence assessed by the Number of days covered method was also associated with not working in patients with PAH (OR 0.595; 95\% CI 0.357-0.991).

\section{Concomitant treatments}

Diuretics, $\beta$-blockers, statins and calcium channel blockers were the most commonly used chronic concomitant treatments for all patients. Patients with IPAH/HPAH that had a positive vasoreactivity test 
at time of diagnosis and who did not receive any other $\mathrm{PH}$-targeted treatment at the time of the present study were not included among those reported using calcium channel blockers as concomitant treatment. Patients with $\mathrm{PAH}$ were more often treated with a chronic concomitant treatment than patients with CTEPH (table 5). Antidiabetic drugs and treatment for hypothyroidism were twice as common among patients with PAH as for patients with CTEPH (table 5).

Of temporary treatments, $67 \%$ of the patients were treated with antibiotics at least once during the study period and $51 \%$ of the patients filled a prescription for a proton pump inhibitor (table 5). Other common drugs were treatments for obstipation and anaemia as well as steroids, asthma inhalers and antifungal crème/solution for external use.

\section{Discussion}

The main finding of the present study was that the overall adherence to oral ERA and/or PDE-5i/SGCs treatment was $60-65 \%$. Adherence was associated with time since diagnosis, especially in patients with $\mathrm{PAH}$, and with number of concomitant chronic treatments in patients with CTEPH. Sex, age or socioeconomic factors, such as level of education, income or marital status, did not affect adherence.

\begin{tabular}{|c|c|c|c|}
\hline & All & PAH & CTEPH \\
\hline Subjects $n$ & 571 & 384 & 187 \\
\hline Age years & $61 \pm 16$ & $58 \pm 16$ & $67 \pm 14$ \\
\hline Age men years & $64 \pm 15$ & $60 \pm 15$ & $68 \pm 14$ \\
\hline Age women years & $60 \pm 17$ & $58 \pm 17$ & $67 \pm 15$ \\
\hline Sex (women) & $349(61)$ & $269(70)$ & $80(43)$ \\
\hline Time since diagnosis years & $4.6 \pm 4.2$ & $4.8 \pm 4.4$ & $4.2 \pm 3.3$ \\
\hline \multicolumn{4}{|l|}{ Highest level of education } \\
\hline Primary school & $147(26)$ & $97(25)$ & 50 (27) \\
\hline High school & 264 (47) & $183(48)$ & $81(43)$ \\
\hline College/University & $147(26)$ & $93(24)$ & 54 (29) \\
\hline \multicolumn{4}{|l|}{ Occupation } \\
\hline Working & 152 (27) & 103 (27) & $49(26)$ \\
\hline$<65 / \geqslant 65$ years & $135(89) / 17(11)$ & $98(95) / 5(5)$ & $37(76) / 12(24)$ \\
\hline Men/women & $62(41) / 90(59)$ & $30(29) / 73(71)$ & $32(65) / 17$ (35) \\
\hline Not working & 419 (73) & $281(73)$ & $138(73)$ \\
\hline$<65 / \geqslant 65$ years & $149(36) / 270(64)$ & 126 (45)/155 (55) & $23(17) / 115(83)$ \\
\hline Men/women & $161(38) / 258(62)$ & $85(30) / 196(70)$ & $76(55) / 62(45)$ \\
\hline \multicolumn{4}{|l|}{ Marital status } \\
\hline Married/registered partner & $257(45)$ & $164(43)$ & $93(50)$ \\
\hline Not married/divorced/widowed & $314(55)$ & $220(57)$ & $94(50)$ \\
\hline \multicolumn{4}{|c|}{ Number of households with children living at home } \\
\hline 0 children in household & 447 (78) & $286(74)$ & $161(86)$ \\
\hline 1 child in household & $70(12)$ & $56(15)$ & $14(7)$ \\
\hline 2 children in household & $38(7)$ & $32(8)$ & $6(3)$ \\
\hline$\geqslant 3$ children in household & $16(3)$ & $10(3)$ & 6 (3) \\
\hline \multicolumn{4}{|c|}{ Number of individual children in different age groups living at home } \\
\hline $0-6$ years & $31(19)$ & 25 (19) & 6 (18) \\
\hline $7-19$ years & $80(48)$ & $67(51)$ & $13(38)$ \\
\hline$\geqslant 20$ years & 55 (33) & $40(30)$ & $15(44)$ \\
\hline \multicolumn{4}{|l|}{ Disposable income (kSEK) } \\
\hline Individual & $202 \pm 137$ & $193 \pm 134$ & $221 \pm 142$ \\
\hline Men & $234 \pm 157$ & $219 \pm 166$ & $249 \pm 146$ \\
\hline Women & $181 \pm 118$ & $181 \pm 116$ & $182 \pm 126$ \\
\hline Household & $340 \pm 274$ & $337 \pm 290$ & $346 \pm 239$ \\
\hline Men & $361 \pm 233$ & $352 \pm 239$ & $371 \pm 227$ \\
\hline Women & $327 \pm 297$ & $331 \pm 309$ & $313 \pm 251$ \\
\hline
\end{tabular}

Data are presented as mean \pm SD or $n(\%)$, unless otherwise stated. $\mathrm{PAH}$ : pulmonary arterial hypertension; CTEPH: chronic thromboembolic pulmonary hypertension. \#: Average disposable income in Sweden 2016-17 was 360 kSEK (www.scb.se/en/finding-statistics/statistics-by-subject-area/household-finances/ income-and-income-distribution/income-and-tax-statistics/pong/tables-and-graphs/income-householdsthe-entire-country/disposable-income-by-type-of-household-2011-2017//. 


\begin{tabular}{|c|c|c|c|}
\hline & All & PAH & CTEPH \\
\hline Subjects $n$ & 571 & 384 & 187 \\
\hline Endothelin receptor antagonists & $346(60)$ & 289 (75) & 57 (30) \\
\hline Phosphodiesterase type 5 inhibitors/soluble guanylate cyclase stimulator & $370(65)$ & 265 (69) & $105(56)$ \\
\hline Prostacyclin analogues & 68 (12) & $60(16)$ & $8(4)$ \\
\hline Single & $217(38)$ & $137(36)$ & $80(43)$ \\
\hline ERA & 80 & 65 & 15 \\
\hline PDE-5i/SGC & 106 & 43 & 63 \\
\hline PRO & 2 & 0 & 2 \\
\hline $\mathrm{CCB}$ & 29 & 29 & \\
\hline Double & 214 (37) & $175(46)$ & $39(21)$ \\
\hline ERA+PDE-5i/SGC & 204 & 167 & 37 \\
\hline $\mathrm{ERA}+\mathrm{PRO}$ & 6 & 5 & 1 \\
\hline PDE-5i/SGC+PRO & 4 & 3 & 1 \\
\hline Triple & $56(10)$ & $52(14)$ & $4(2)$ \\
\hline ERA+PDE-5i/SGC+PRO & 56 & 52 & 4 \\
\hline Untreated & $84(15)$ & $20(5)$ & $64(35)$ \\
\hline \multicolumn{4}{|l|}{ Anticoagulants } \\
\hline Warfarin & $349(61)$ & 180 (47) & 169 (90) \\
\hline Other & $92(16)$ & 74 (19) & $18(10)$ \\
\hline Oxygen & 52 (9) & $37(10)$ & $15(8)$ \\
\hline \multicolumn{4}{|c|}{$\begin{array}{l}\text { Data are presented as } n \text { or } n(\%) \text {. PAH: pulmonary arterial hypertension; CTEPH: chronic thromboembolic } \\
\text { pulmonary hypertension; ERA: endothelin receptor antagonists; PDE-5i: phosphodiesterase type } 5 \\
\text { inhibitors; SGCs: soluble guanylate cyclase stimulator; PRO: prostacyclin analogues; CCB: calcium } \\
\text { channel blockers. }\end{array}$} \\
\hline
\end{tabular}

The present study used a strict method for treatment adherence, allowing only one missed daily dosage per month to be categorised as low adherence. In support of this method, the overall adherence to PAH treatment found in the study was in good concordance with the self-reported treatment adherence of $57 \%$ from the Swedish PAH and CTEPH population that has been published earlier [7]. The patient's perception of adverse side-effects that might occur has been shown to affect the patient's decision whether to take the drugs as prescribed or not $[15,16]$. In addition, previous experiences with pharmacological therapies might lead to a lack of motivation to adhere to a treatment [17]. Thus, it is important to address

\section{TABLE 3 Adherence to pulmonary hypertension-specific treatment}

All

Number \% Adherence \% Adherence included (NoDC)
PAH (Man)

\section{Number \% Adherence \% Adherence included (NoDC) \\ (Man)}

\begin{tabular}{lcc} 
& CTEPH \\
\hline $\begin{array}{l}\text { Number } \\
\text { included }\end{array}$ & $\begin{array}{c}\text { Adherence } \\
\text { (NoDC) }\end{array}$ & $\begin{array}{c}\text { Adherence } \\
\text { (Man) }\end{array}$
\end{tabular}

\section{ERA}

$\begin{array}{lcc}\text { Ambrisentan } & 99 & 87 \\ \text { Bosentan } & 98 & 71 \\ \text { Macitentan } & 166 & 8 \\ \begin{array}{l}\text { PEE-5i } \\ \text { Sildenafil }\end{array} & 207 & 6 \\ \text { Tadalafil } & 137 & 80 \\ \text { GCs } & & \\ \text { Riociguat } & 32 & 91 \\ \text { Single treatment } & 209 & 68 \\ \text { Double treatment } & 234 & 6 \\ \text { Oral\#+PRO } & 66 & 74\end{array}$

Data are presented as number of patients who filled a prescription and were included in the analyses, and proportion of those with good adherence shown for Number of days covered (NoDC) and Manual assessment (Man) methods. PAH: pulmonary arterial hypertension; CTEPH: chronic thromboembolic pulmonary hypertension; ERA: Endothelin receptor antagonists; PDE-5i: Phosphodiesterase type 5 inhibitors; SGCs: Soluble guanylate cyclase stimulator; PRO: prostacyclin therapy. ${ }^{\#}$ : Adherence to oral treatment reported.

\begin{tabular}{|c|c|c|c|c|c|c|c|}
\hline 87 & 83 & 90 & 87 & 82 & 9 & 89 & 89 \\
\hline 71 & 66 & 73 & 71 & 68 & 25 & 72 & 60 \\
\hline 84 & 78 & 146 & 82 & 77 & 20 & 95 & 90 \\
\hline 60 & 61 & 146 & 61 & 62 & 61 & 59 & 59 \\
\hline 80 & 74 & 117 & 80 & 74 & 20 & 80 & 75 \\
\hline 91 & 91 & 2 & 0 & 0 & 30 & 90 & 90 \\
\hline 68 & 65 & 131 & 69 & 66 & 78 & 67 & 63 \\
\hline 64 & 59 & 198 & 64 & 58 & 36 & 67 & 67 \\
\hline 74 & 70 & 60 & 73 & 70 & 6 & 83 & 83 \\
\hline
\end{tabular}



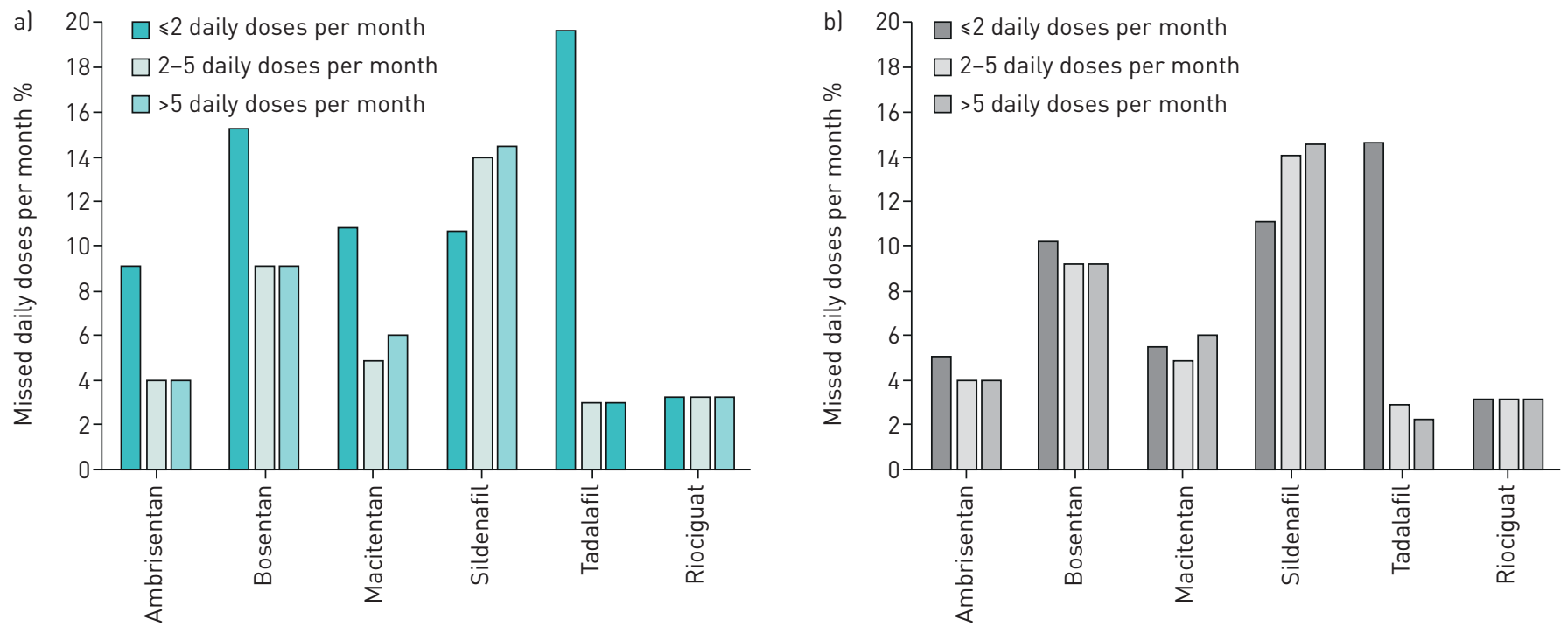

FIGURE 1 Proportion of low adherence by number of missed daily dosages per month shown for the manual assessment (a) and number of days covered (b) methods.

the patient's concerns about a treatment, both at the time of first prescription and at subsequent meetings with the patient $[18,19]$. As shown in the present study, as well as in earlier studies, adherence to treatment decreases over time $[7,8]$.

In the present study, of those who did not meet the criteria of adherence, and with the exception of treatment with sildenafil, approximately half missed two or less daily dosages per month. This might be considered a medium level of adherence, while the quarter that missed more than five daily dosages per month might be at a low level. Patients on sildenafil would then be reckoned as a third in each category of medium, medium-low and low adherence. The effect adherence to $\mathrm{PH}$ treatments has on disease progression is not known. Neither is the threshold of adherence that should be considered low. While not taking the medication once or twice in a month might not seem a problem, the present study investigated prescription fill over a 2-year period. Thus, the number of daily dosages not taken represent an average of missed daily dosages per month over a longer period.

\section{TABLE 4 Logistic regression analysis showing the relationship between adherence and explanatory variables}

\begin{tabular}{|c|c|c|c|}
\hline & All & PAH & CTEPH \\
\hline Subjects $n$ & 571 & 384 & 187 \\
\hline Sex (female versus male) & $0.725(0.486-1.081)$ & $0.704(0.434-1.144)$ & $0.808(0.374-1.746)$ \\
\hline Age $(\leqslant 65$ years versus $>65$ years $)$ & $0.749(0.510-1.100)$ & $0.725(0.461-1.141)$ & $0.870(0.379-1.995)$ \\
\hline \multicolumn{4}{|l|}{ Time since diagnosis } \\
\hline$\leqslant 1$ year versus $>1$ year & $2.036(1.201-3.454)$ & $1.813(0.998-3.294)$ & $3.027(0.948-9.664)$ \\
\hline Education (primary/high school versus college/university) & $0.930(0.597-1.448)$ & $1.082(0.644-1.818)$ & $0.605(0.256-1.429)$ \\
\hline $\begin{array}{l}\text { Marital status (married/registered partner versus not } \\
\text { married/divorced/widowed) }\end{array}$ & $1.138(0.774-1.671)$ & $1.120(0.717-1.751)$ & $1.154(0.536-2.484)$ \\
\hline Children living at home (yes versus no) & $0.865(0.538-1.393)$ & $0.985(0.579-1.674)$ & $0.515(0.167-1.589)$ \\
\hline Working (yes versus no) & $0.782(0.503-1.216)$ & $0.683(0.413-1.131)$ & $1.252(0.487-3.219)$ \\
\hline Household income ( $\leqslant$ median versus $>$ median $\left.^{\#}\right)$ & $1.142(0.760-1.717)$ & $1.009(0.627-1.623)$ & $1.642(0.740-3.645)$ \\
\hline
\end{tabular}




\begin{tabular}{|c|c|c|c|}
\hline & All & PAH & CTEPH \\
\hline Subjects $\mathrm{n}$ & 571 & 384 & 187 \\
\hline \multicolumn{4}{|c|}{ Chronic treatment $1 \geqslant 3$ filled prescriptions per year) } \\
\hline Angiotensin-converting enzyme inhibitors & 108 (19) & $81(21)$ & $27(14)$ \\
\hline Angiotensin receptor blockers & $101(18)$ & $65(17)$ & $36(19)$ \\
\hline$\beta$-blockers & $226(40)$ & $156(41)$ & 70 (37) \\
\hline Calcium channel blockers & $138(24)$ & $106(28)$ & $32(17)$ \\
\hline Anti-arrhythmia drugs & $82(14)$ & $61(16)$ & $21(11)$ \\
\hline Statins & $174(30)$ & $123(32)$ & $51(27)$ \\
\hline Diuretics & $380(66)$ & $267(70)$ & $113(60)$ \\
\hline Antidiabetics & $80(14)$ & $67(17)$ & $13(7)$ \\
\hline Thyroid replacement hormones & $88(15)$ & $69(18)$ & $19(10)$ \\
\hline \multicolumn{4}{|c|}{ Number of patients that filled prescriptions for chronic treatments $1 \geqslant 3$ per year) } \\
\hline 0 & $83(15)$ & $45(12)$ & $38(20)$ \\
\hline 1 & $103(18)$ & $58(15)$ & $45(24)$ \\
\hline 2 & $114(20)$ & $78(20)$ & $36(19)$ \\
\hline 3 & $117(20)$ & $86(22)$ & $31(16)$ \\
\hline 4 & 75 (13) & $54(14)$ & $21(11)$ \\
\hline 5 & 51 (9) & $42(11)$ & $9(5)$ \\
\hline$\geqslant 6$ & $29(5)$ & $21(6)$ & 8 (5) \\
\hline \multicolumn{4}{|c|}{ Temporary treatment $(\geqslant 1$ filled prescriptions per year) } \\
\hline Drugs for anaemia & $146(26)$ & $107(28)$ & $39(21)$ \\
\hline Antibiotics & $384(67)$ & $275(72)$ & 109 (58) \\
\hline Antihistamines & $101(18)$ & $68(18)$ & 33 (18) \\
\hline Antiviral drugs & $51(9)$ & $44(11)$ & $7(4)$ \\
\hline Asthma oral therapy & $12(2)$ & $7(2)$ & 5 (3) \\
\hline Asthma inhaler therapy & $171(30)$ & $119(31)$ & $52(28)$ \\
\hline Antidiarrhoeal drugs & $79(14)$ & $62(16)$ & $17(9)$ \\
\hline Anti-emetics & $61(11)$ & $52(14)$ & $9(5)$ \\
\hline Anti-acid drugs & $47(8)$ & $41(11)$ & $6(3)$ \\
\hline Proton pump inhibitors & $294(51)$ & 219 (57) & $75(40)$ \\
\hline Laxatives & $204(36)$ & 143 (37) & $61(32)$ \\
\hline Antifungal - oral therapy & $2(<1)$ & $2(1)$ & 0 \\
\hline Antifungal - cutaneous/solution & 191 (33) & 142 (37) & $49(26)$ \\
\hline Steroids - oral therapy & $177(31)$ & $132(34)$ & $45(24)$ \\
\hline \multicolumn{4}{|c|}{ Number of patients that filled prescriptions for temporary treatments ( $\geqslant 1$ per year) } \\
\hline 0 & $56(10)$ & $30(8)$ & $26(14)$ \\
\hline 1 & $79(14)$ & $43(11)$ & 36 (19) \\
\hline 2 & 100 (17) & $64(17)$ & $36(19)$ \\
\hline 3 & 73 (13) & 45 (12) & $28(15)$ \\
\hline 4 & $92(16)$ & $69(18)$ & $23(12)$ \\
\hline$\geqslant 5$ & $172(30)$ & $133(35)$ & $39(21)$ \\
\hline
\end{tabular}

Data are presented as $\mathrm{n}(\%)$, unless otherwise stated. $\mathrm{PAH}$ : pulmonary arterial hypertension; CTEPH: chronic thromboembolic pulmonary hypertension.

Adherence to $\mathrm{PH}$ treatment varied from a $91 \%$ adherence to riociguat to a $60 \%$ adherence to sildenafil in the present study. However, these results should be interpreted with caution. The use of riociguat was approved in Sweden the year before the present study, and only a small proportion of the patients, and almost all with CTEPH, were treated with it. Both sildenafil and riociguat are prescribed three times a day, a treatment regimen that has previously been associated with low adherence $[5,8,10,20]$. With riociguat being the only drug in Sweden approved for CTEPH at the present time, this might support a high adherence, at least initially [21]. In addition, riociguat requires more frequent contact with the PAH clinic during the dose-adjustment period, which might also lead to higher adherence. With the exception of riociguat, and in concordance with earlier results, treatments administered once a day had the best adherence $[8,20]$.

There was no association between adherence and number of PH treatments in the present study. This is in contrast to a previous study by STUDER et al. [10] that showed that patients on combination therapy had higher adherence. Study design and treatment regimen probably explain some of the differences. Patients in that study were newly diagnosed, and only a quarter of the identified patients met the inclusion criteria 
and were investigated. A majority were treated with monotherapy, in particular PDE-5i, after diagnosis, and at the end of the 12 months the study lasted, 75\% were still being treated with only one $\mathrm{PH}$ treatment [10]. In the present study, only $38 \%$ were treated with monotherapy during the course of the study. Time since diagnosis and number of concomitant chronic drugs were the only investigated variables that showed an association with low adherence in the present study, the latter probably reflecting a higher comorbidity burden $[8,22]$. Similar results have been shown in two previous studies using self-reported adherence instruments [7, 8]. However, both those studies showed an association with higher age that was not present in the current study. In addition, GRADY et al. [8] showed an association between monotherapy and adherence, while IVARSSON et al. [7], similar to the present study, saw no association between either single or combination PH treatment and adherence. The discrepancy between the results might be related to the low proportion of patients on combination therapy in the GraDY et al. [8] study.

All patients included in the present study have regular contact with the PAH/CTEPH-expert centres [23], which may have increased their understanding of the PAH disease, improved involvement in treatment decision and supported good medical literacy, factors that have been related to adherence [17, 24]. Building trust between patients, caregivers and staff might affect the patient's health beliefs and attitudes concerning the effectiveness of the treatment $[19,24,25]$. However, this might also have an opposite effect as the healthcare staff feel they know the patient, and thus, information about the disease and the importance of treatment is not repeated regularly, leading to declining adherence over time. In a recent study it was shown that despite agreeing that they received appropriate information, about half of the patients wanted more information [26].

High costs or co-payments for treatment and healthcare have been shown to contribute to poor medication adherence [17, 27]. However, in the present study there was no relation between socioeconomic factors and adherence, despite the household income being at, or slightly lower than, the average disposable income in Sweden. The cost ceiling in the Swedish healthcare system that covers almost all costs related to care, including drug prescriptions, probably contributed to this finding.

The rather high proportion of patients in the present study that filled three or more prescriptions of treatments for other chronic diseases indicates that comorbidities were common in this patient population. In addition, prescriptions for temporary treatments such as antibiotics, proton pump inhibitors and other treatments related to digestive symptoms were also frequently filled. This might be related to side-effects of the PAH-specific drugs or might mirror the comorbidity burden related to increasing mean age of the PAH patients, seen all over the world $[28,29]$. The number of patients prescribed antibiotics, about two thirds of the study population, was surprisingly high. One might speculate that some overuse of antibiotics to avoid severe infections in these patients might occur, especially as patients generally contact the primary care service for common colds and infections. The PAH/CTEPH-expert centres are essential for coordinating the contacts with other parts of the healthcare system, such as being accessible for questions from the primary caregivers in the context of these rare diagnoses [30].

A quarter of the patients with PAH had children living at home, and of those, two thirds were 19 years old or younger showing that it is a disease that still affects the young in high proportion $[1,29]$. In this study, there was no relation between age, sex or the family situation to treatment adherence. The proportion of patients living alone was higher than in the general Swedish population, a finding in concordance with other reports that divorce is not uncommon in this patient group [31]. However, there was no relation between marital status and adherence in the present study, despite an earlier study showing that spouses want to support treatment adherence to prolong life for their partner [32].

It is obvious that low treatment adherence will contribute to suboptimal clinical benefits. This has further been highlighted by the World Health Organization (WHO), which stated that increasing adherence may have a greater effect on health than any improvement in specific medical treatments [28]. It has been suggested that the best strategy to improve treatment adherence is to involve the patient in the medical decision process and stress the immediate advantages of treatment instead of future complications [17].

\section{Methodological considerations}

The adequate sample size in the form of a national cohort of patients alive in 2016-2017 recorded in a register with $>90 \%$ national coverage is a strength. The proportion of patients with PAH and CTEPH are in alignment with the proportions of patients in the Swedish PAH registry [11]. The analysis of adherence was based on filled prescriptions, and thus, the study has assumed that this reflects the patients actually taking the drug they have collected from the pharmacy. Adherence to prostacyclin analogues and the prostacyclin receptor agonist was not analysed due to the individualised dosages that are used for this group of drugs. In the analysis of other temporary treatments, there is probably a suboptimal reporting of 
treatments such as antifungals, antihistamines and treatments for gastrointestinal symptoms, which can be purchased without a prescription in Sweden.

\section{Conclusions}

Adherence to oral ERA and/or PDE-5i/SGCs treatment was $60-65 \%$ and associated with time since diagnosis and with number of concomitant chronic treatments. Sex, age or socioeconomic factors, such as level of education, income or marital status, did not affect adherence.

Acknowledgements: We acknowledge the work of the SPAHR registrars at the PAH centres, Uppsala Clinical Research Centre and members of the SPAHR steering committee.

Support statement: This study was supported by the Medicine Service University Trust, Region Skåne and by an unrestricted research grant from Actelion Pharmaceuticals Sverige AB. Funding information for this article has been deposited with the Crossref Funder Registry.

Conflict of interest: None declared.

\section{References}

1 Galiè N, Humbert M, Vachiery J-L, et al. ESC/ERS Guidelines for the diagnosis and treatment of pulmonary hypertension: the Joint Task Force for the Diagnosis and Treatment of Pulmonary Hypertension of the European Society of Cardiology (ESC) and the European Respiratory Society (ERS): endorsed by: Association for European Paediatric and Congenital Cardiology (AEPC), International Society for Heart and Lung Transplantation (ISHLT). Eur Heart J 2015; 2015: 67-119.

2 Rådegran G, Kjellström B, Ekmehag B, et al. Characteristics and survival of adult Swedish PAH and CTEPH patients 2000-2014. Scand Cardiovasc J 2016; 50: 243-250.

3 Galiè N, Channick RN, Frantz RP, et al. Risk stratification and medical therapy of pulmonary arterial hypertension. Eur Respir J 2019; 53: 1801889.

4 Strange G, Manterfield C, Miller T, et al. Non-parenteral therapy for pulmonary arterial hypertension: a review of efficacy, tolerability and factors related to patient adherence. Clin Med Insights Ther 2011; 3: 113-124

5 Waxman A, Chen SY, Boulanger L, et al. Factors associated with adherence to phosphodiesterase type 5 inhibitors for the treatment of pulmonary arterial hypertension. J Med Econ 2013; 16: 298-306.

6 Yorke J, Armstrong I, Bundock S. Impact of living with pulmonary hypertension: a qualitative exploration. Nurs Health Sci 2014; 16: 454-460.

7 Ivarsson $\mathrm{B}$, Hesselstrand $\mathrm{R}$, Rådegran $\mathrm{G}$, et al. Adherence and medication belief in patients with pulmonary arterial hypertension or chronic thromboembolic pulmonary hypertension: a nationwide population-based cohort survey. Clin Respir J 2018; 12: 2029-2035.

8 Grady D, Weiss M, Hernandez-Sanchez J, et al. Medication and patient factors associated with adherence to pulmonary hypertension targeted therapies. Pulm Circ 2018; 8: 2045893217743616.

9 Shah NB, Mitchell RE, Proctor ST, et al. High rates of medication adherence in patients with pulmonary arterial hypertension: an integrated specialty pharmacy approach. PLoS One 2019; 14: e0217798.

10 Studer S, Hull M, Pruett J, et al. Treatment patterns, healthcare resource utilization, and healthcare costs among patients with pulmonary arterial hypertension in a real-world US database. Pulm Circ 2019; 9: 2045894018816294.

11 Swedish Pulmonary Arterial Hypertension Registry Annual Report 2019. (SPAHR Årsrapport 2019). www.ucr.uu. se/spahr/ Date last updated: March 18, 2020. Date last accessed: March 18, 2020.

12 Socialstyrelsen (Swedish National Board of Health and Welfare). The Prescribed Drug Register at the Swedish National Board of Health and Welfare [in Swedish]. www.socialstyrelsen.se/statistik-och-data/register/alla-register/ lakemedelsregistret/ Date last updated: March 14, 2020. Date last accessed: March 14, 2020.

13 Statistiska centralbyrån (Statistics Sweden). Longitudinal integrated database for health insurance and labour market studies (LISA). www.scb.se/en/services/guidance-for-researchers-and-universities/vilka-mikrodata-finns/ longitudinella-register/longitudinal-integrated-database-for-health-insurance-and-labour-market-studies-lisa/ Date last updated: March 14, 2020. Date last accessed: March 14, 2020.

14 Andrade SE, Kahler KH, Frech F, et al. Methods for evaluation of medication adherence and persistence using automated databases. Pharmacoepidemiol Drug Saf 2006; 15: 565-574.

15 Ivarsson B, Ekmehag B, Sjoberg T. Support experienced by patients living with pulmonary arterial hypertension and chronic thromboembolic pulmonary hypertension. Heart Lung Circ 2016; 25: 35-40.

16 Svensson S, Kjellgren KI, Ahlner J, et al. Reasons for adherence with antihypertensive medication. Int J Cardiol 2000; 76: 157-163.

17 Brown MT, Bussell JK. Medication adherence: WHO cares? Mayo Clin Proc 2011; 86: 304-314.

18 Narechania S, Torbic H, Tonelli AR. Treatment discontinuation or interruption in pulmonary arterial hypertension. J Cardiovasc Pharmacol Ther 2020; 25: 131-141.

19 Lombardi S, Kingman M, Duncan M, et al. Titration of pulmonary arterial hypertension therapeutics: experience-based recommendations. Respir Med 2018; 143: 139-146.

20 Claxton AJ, Cramer J, Pierce C. A systematic review of the associations between dose regimens and medication compliance. Clin Ther 2001; 23: 1296-1310.

21 Ghofrani HA, D'Armini AM, Grimminger F, et al. Riociguat for the treatment of chronic thromboembolic pulmonary hypertension. N Engl J Med 2013; 369: 319-329.

22 Lang IM, Palazzini M. The burden of comorbidities in pulmonary arterial hypertension. Eur Heart J Suppl 2019; 21: K21-K28.

23 Kjellström B, Ryftenius H, Landenfelt-Gestre L-L, et al. EXPRESS: Outpatient specialist clinics for pulmonary arterial hypertension and chronic thromboembolic pulmonary hypertension in the Nordic countries. Pulm Circ 2019; 10: 2045894019897499. 
24 Burks M, Stickel S, Galie N. Pulmonary arterial hypertension: combination therapy in practice. Am J Cardiovac Drug 2018; 18: 249-257.

25 Shah RB, Desai SV, Gajjar BM, et al. Factors responsible for noncompliance to drug therapy in the elderly and the impact of patient education on improving compliance. Drugs Ther Perspect 2013; 29: 360-366.

26 Ivarsson B, Rådegran G, Hesselstrand R, et al. Information, social support and coping in patients with pulmonary arterial hypertension or chronic thromboembolic pulmonary hypertension: a nationwide population-based study. Patient Educ Couns 2017; 100: 936-942.

27 Frantz R, Roberts WM, Hill JW, et al. EXPRESS: Medication adherence, hospitalization, and healthcare resource utilization and costs in patients with pulmonary arterial hypertension treated with endothelin receptor antagonists or phosphodiesterase type-5 inhibitors. Pulm Circ 2020; 10: 2045894019880086.

28 Sabaté E. Adherence to long-term therapies: evidence for action. Geneva, WHO, 2003.

29 Hjalmarsson C, Rådegran G, Kylhammar D, et al. Impact of age and comorbidity on risk stratification in idiopathic pulmonary arterial hypertension. Eur Respir J 2018; 51: 1702310.

30 Gin-Sing W. Pulmonary arterial hypertension: a multidisciplinary approach to care. Nurs Stand 2010; 24: 40-47.

31 Wryobeck JM, Lippo G, McLaughlin V, et al. Psychosocial aspects of pulmonary hypertension: a review. Psychosomatics 2007; 48: 467-475.

32 Ivarsson B, Sjöberg T, Hesselstrand R, et al. Everyday life experiences of spouses of patients who suffer from pulmonary arterial hypertension or chronic thromboembolic pulmonary hypertension. ERJ Open Res 2019; 5: 00218-2018. 